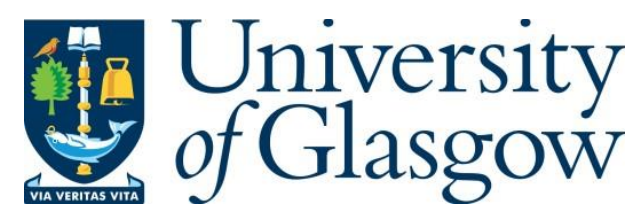

Abhayawansa, S., Aleksanyan, M. and Cuganesan, S. (2018) Conceptualisation of intellectual capital in analysts' narratives: a performative view. Accounting, Auditing and Accountability Journal, 31(3), pp. 950-969.

There may be differences between this version and the published version. You are advised to consult the publisher's version if you wish to cite from it.

http://eprints.gla.ac.uk/144061/

Deposited on: 11 July 2017

Enlighten - Research publications by members of the University of Glasgow http://eprints.gla.ac.uk 


\title{
Conceptualisation of Intellectual Capital in Analysts' Narratives: A Performative View
}

\begin{abstract}
Purpose - This study tests the performativity of Intellectual Capital (IC) from the perspective of sell-side analysts, a type of actor who consumes and creates IC information and in whose practice IC information plays a significant role.
\end{abstract}

Design/methodology/approach - The empirical component of the study comprises a narrative analysis of the text of a large corpus of sell-side analysts' initiation coverage reports. We adopt Mouritsen's (2006) performative and ostensive conceptualisations of IC as our theoretical framework.

Findings - We find that the identities and properties of IC elements are variable, dynamic and transformative. The relevance of IC elements in the eyes of analysts is conditional on the context, temporally contingent and bestowed indirectly. IC elements are attributed to firm value both directly, in a linear manner, and indirectly, via various non-linear interrelationships established with other IC elements, tangible capital and financial capital.

Research limitations/implications - This study challenges the conventional IC research paradigm and contributes towards a performativity-inspired conceptualisation of IC and a resultant situated model of IC in place of a predictive model.

Originality/value -This is the first study to apply a performative lens to study IC identities, roles and relationships from the perspective of a field of practice that is external to the organisation where IC is hosted. Examining IC from analysts' perspective is important because not only can it provide an alternative perspective of IC, it also enables an understanding of analysts' field of practice.

Keywords intellectual capital, performative view, sell-side analysts, narrative analysis

Paper type Research paper 


\section{Conceptualisation of Intellectual Capital in Analysts' Narratives: A Performative View}

\section{Introduction}

The topic of intangibles, or intellectual capital (IC), has been attracting significant scholarly attention for nearly two decades. The established narrative within this research theorises IC as a typology of separate elements categorised into human, structural and relational capital, whose properties are known and measurable, and whose roles and effects on value creation are predetermined. Mouritsen (2006) calls into question and contests this well-established IC paradigm. By invoking Latour's performative and ostensive dichotomy, Mouritsen (2006) proposes that the identities, roles and relationships typically ascribed to IC based on positivistic epistemology may not be 'typical' and predetermined at all, particularly when viewed critically or from the perspective of different practices. This performative theorisation of IC has opened up IC research to new lines of inquiry and potential understandings of the IC phenomenon. Indeed, several eminent IC researchers have argued that the next stage of IC research should be based on a critical performative analysis of IC practices in action (Dumay, 2014; Guthrie et al., 2012; Mouritsen, 2006). However, empirical research into the performativity of IC is only beginning to emerge (e.g., Murthy and Mouritsen, 2011; Veltri and Bronzetti, 2015), and more needs to be done to examine the performativity of IC from a perspective of a field of practice that is external (yet fundamentally important) to the organisation where IC is hosted.

Our study responds to the calls for performative IC research, and empirically scrutinises Mouritsen's (2006) conceptualisation of IC by using as a context one field of practice where IC information has been found to play a crucial role - the practice of financial (sell-side) analysts (see Abhayawansa et al., 2015). We adapt Mouritsen's (2006) performative and ostensive conceptualisations of IC to examine: (1) what identities and properties of IC elements are (re)constructed and mobilised by analysts; (2) how relevance of IC elements is determined from the point of view of analysts; and (3) how analysts relate (connect) IC elements to each other and firm value. In answering these research questions, we invariably dwell on the questions of 'what does IC do?' and 'how is IC related to value'; two questions Mouritsen (2006, p.837) argues "open debate about the fragile existence of IC" and "get beyond what is taken for granted in IC research". As O'Donnell et al. (2006) contend, asking the how question is important and revealing because it addresses the practice of IC in organisations (or, in our case, IC in the practice of analysts), rather than re-creating a static representation of IC, as is represented by contemporary measurement frameworks and their associated theories. 
In the field of investment advice, sell-side analysts occupy centre court. They act as information and knowledge intermediaries between companies whose shares are traded on the stock market and institutional investors in the shares of these companies. Sell-side analysts' principal task is to empower their clients' investment decisions by debunking and performing 'sense-making' of complex information. Prior research shows that analysts mobilise and combine non-IC and IC-type information that they perceive as relevant to perform fundamental analysis and value companies they cover, and to generate convincing narratives, culminating in investment advice in the form of written research reports. Prior research tells us that analysts' use of IC information is extensive (Abhayawansa and Guthrie, 2012; García-Meca and Martínez, 2007; Orens and Lybaert, 2007), and IC information plays a non-trivial role in analysts' valuations of companies and investment recommendations (Abhayawansa et al., 2015). Due to substantial subjectivity, complexity and idiosyncrasy involved in analysts' gathering, analysis and interpretation of information, the practice of equity research is often regarded as being as much art as science (Damodaran, 2008). The possibility that there may exist a multitude of ways in which different analysts may choose to mobilise information to create convincing investment narratives suggests that this topic is inherently complex. In the context of sell-side analysts' practice, researchers should not assume that analysts would be ascribing to IC identities, roles and relationships typically ascribed to IC in positivistic organisational studies, within an organisational context and, indeed, some recent analyst literature. Therefore, how analysts conceptualise IC and ascribe various properties and relationships to it requires investigation for a more nuanced understanding of the topic.

To our knowledge, this is the first study that applies a performative lens to issues of IC identity, roles and relationships within the context of the practice of sell-side analysts. This is despite the fact that analysts' research is a highly impactful area of professional practice - an area of practice that ensures efficient information processing and capital allocation decisions by investors, and overall effective functioning of capital markets (Schipper, 1991).

To answer our research questions, we conduct a narrative analysis of the text of a large corpus of sell-side analysts' initiation coverage reports. We choose initiation reports because they represent analysts' most rigorously and comprehensively documented information processing and thought process, and are meant to be the most detailed narrative that analysts would generate to pitch to investors their investment advice in relation to a given company. 
Our findings are that in the eyes of analysts, the identities and properties of IC are variable, dynamic and transformative, and there often exist non-linear, contingent relationships among IC elements and between IC elements and financial capital (hereafter FC). Thus, the properties, roles and relationships of IC elements cannot be determined a priori but in association with other elements and constructs in firms' value-creation processes and stories. Our findings support a performativity-inspired conceptualisation of IC - i.e., IC as a boundary object, one that is "weakly structured in common use and become[s] strongly structured in individual-site use" (Bowker and Star, 1999, p.297) - and a resultant situated model of IC in place of a predictive model.

The paper is organised as follows. Section 2 theorises our research and reviews relevant literature. Section 3 details the research design. Section 4 presents the main results. Section 5 discusses the findings and concludes the paper.

\section{Theoretical background and prior literature}

\subsection{Theorising IC research: 'traditional' ostensive paradigm vs. 'new' performative view}

Mouritsen (2006) uses Latour's (1986) ostensive and performative dichotomy to illustrate different theoretical choices for studying IC in practice. The ostensive notion implies that the links, relationships and properties that are typical of society and the activities of social actors can be objectively determined. When applied to IC, this research paradigm leads to a search for universal laws or principles about regularities and causal relationships from which hypotheses about how IC creates value in organisations may be deduced (see also Chua, 1986). In the ostensive view of IC, each IC element is endowed with fixed functional properties and identities distinct from those of other IC elements, and financial or tangible capital. The identities and properties of IC elements are thus knowable and clearly definable in theory.

In contrast, the performative notion implies that how elements (e.g., IC) are linked together is, in principle, not explainable in a deterministic and generalisable way, but that in practice, every time someone mobilises those elements, new associations and links are discovered (Latour, 1986, p.273). Here, properties, links and associations are negotiable, practical and revisable matters, and the emphasis shifts from principle to practice. Under the performative premise, IC elements may gain their identity from their relations to other entities, such as strategy or other IC elements, and in different contexts, IC's identities and functional properties may work and manifest in various ways. Thus, IC is to be considered as a representation of knowledge 
resources whose transformative properties and identities emerge in application (Mouritsen, 2006). The performative view can expand the boundaries of IC research, as it acknowledges that no IC element has a single form and function. Holding this view encourages continual rethink and discovery of novel incarnations of IC identities and relationships.

The notion of the relevance of IC also differs according to research paradigm. In the ostensive perspective, all IC elements are by default relevant, and their impact on firm value is determinable. Accordingly, capital markets research can be used to establish the relevance of IC by investigating the historical associations between IC and financial and market-based variables. From a performative perspective, one may not a priori perceive a particular IC element as a value-creating asset or a value driver with a concrete, known and generalisable role within the business. This is because relationships among IC elements are not necessarily stable: IC elements and relationships may display dissimilar features, and they could cease to exist or change intensity, direction and nature over time (Montemari and Nielsen, 2013). As the effects of IC elements are contingent, determining relevance requires IC to be studied in its application in situ and the use of methods other than capitals markets research.

In relation to drawing linkages between IC elements and firm value, the ostensive paradigm assumes causal, sequential and determinable relationships, implying that, in essence, there is a predictive model of IC, known to capital market actors. Thus, research emphasises establishing the normative or positivistic relations between IC (and its measurement) and its effects on organisational decisions, value creation and capital market behaviour. In contrast, the performative paradigm presupposes a situated model of IC where relationships between IC elements and firm value creation are complex, as they are unique to the situation, change over time, contingent on the other IC elements and often non-linear.

Insofar as IC is concerned, the analyst literature has taken an inherently ostensive view (Abhayawansa et al., 2015; García-Meca and Martínez, 2007; Orens and Lybaert, 2007; Simpson, 2010). The research agenda has been limited to ascertaining the extent of analysts' use of IC (or non-financial) information in their fundamental analysis and reports, and explaining how IC information maps onto analysts' valuation parameters and stock recommendations. The ostensive research paradigm does not lend itself to "understanding IC as concept - an object worth studying and not just applying" (Mouritsen, 2006, p.821) from an analyst perspective. However, by shifting to a performative paradigm and viewing analyst reports as containing sense-making narratives (not merely a record of the IC information types 
used in valuations), more interesting research questions can be answered towards a nuanced understanding of IC. As analysts constantly attempt to create non-consensual, original and differentiated narratives in order to secure 'air time' with clients (i.e., buy-side analysts and portfolio managers) for their research to be perceived as valuable, they are expected to mobilise IC idiosyncratically based on their own IC (e.g., analysts' knowledge, cognitive skills, analytical apparatus, social capital). Due to the inherently subjective, 'part art part science' nature of analysts' practice (Damodaran, 2008), there may arguably exist a multitude of such idiosyncrasies of invoking the identities, functional properties, roles and relationships of IC elements in each concrete case of firm value creation. As "IC concepts can be better understood if they are examined through the actual practice of IC" (Dumay, 2012, p.12), an examination of the practice of analysts or indeed an investigation of the sense-making narratives of their reports through a performative lens ought to reveal these.

\subsection{Relevant IC literature}

The ostensive premise underpins a significant body of empirical accounting literature on organisational practices of IC. This stream of research builds on the premises that: (1) the components of IC - human capital, structural capital and relational capital - have properties distinct from one another; (2) all IC components are value-generating (Martín-de-Castro et al., 2011); (3) the relationship between IC components and firm performance or value is linear, sequential and causal (Wang, 2015); and (4) the relationships between IC and firm value are predictable, statistically discoverable and generalisable (Anderson et al., 1997; Andreeva and Garanina, 2016; Kallapur and Kwan, 2004; Wang, 2008). Research of this genre has been successful in ascribing a level of predictability to the relationship between IC components and financial performance, and uses causal maps to model them (Marr et al., 2004; Roos et al., 2005). Invariably, this research upholds IC measurement as essential and legitimises the use of IC measurement frameworks, "attempting to fit IC into a 'one size fits all' framework" (Rooney and Dumay, 2016, p.3). Later studies, such as Montemari and Nielsen (2013), extend IC causal maps by enabling the maps to incorporate the dynamic aspects of IC. Researchers such as Bontis (1998) and Bontis and Fitz-enz (2002) show that there is a common structure of IC relationships between different kind of entities. In this structure, human capital is the precursor to relational and structural capital; relational capital directly affects structural capital, and structural capital directly affects FC (Bontis, 1998; Namasivayam and Denizci, 2006; Wang and Chang, 2005). 
There is research evidence that challenges the validity of a universal structure of IC relationships. For instance, Mouritsen and Koleva (2004) show that the direction of the causality between human capital and the elements of other IC categories could be reversed. Jhunjhunwala (2009) explains through examples that value-creation networks consist of multiple cause-and-effect relations between elements of IC in the forms of one-to-one and oneto-many. Although he depicts these relationships as taking a linear and sequential form, evidence to the contrary also exists. One example is Huang and Liu (2005). They find that there is an optimum level of investment in innovation capital, and further investment beyond this threshold reduces financial performance. Also, they show that IC such as information technology capital does not contribute to financial performance unless there is a significant presence of another element of IC (e.g., innovation capital). This is because some IC elements are directly, as well as indirectly, dependent on each other to create value (Bueno et al., 2006; Marr et al., 2004). Murthy and Mouritsen (2011) show that in the practice of a bank there are trade-offs between IC elements and between IC elements and physical capital and FC due to resource constraints and organisational power play. Their findings call into question the validity of assuming a linear and unidirectional relationship between IC and FC in all contexts.

Research engaged in more critical observations of practice indicates that relationships between IC and value are dynamic and fragile (Catasus et al., 2007; Cuganesan, 2005; Dumay, 2009), with notions of causality precarious at best (Murthy and Mouritsen, 2011). Studying IC in practice, Cuganesan (2005) demonstrates that not only are IC elements interrelated and interdependent, they also transform each other, often in a pluralistic and fluid manner. Mouritsen (2003) explains that IC in the form of competencies is created due to complementarities between various IC elements, and it only exists in instances of their collective performance. Indeed, reviews of IC research highlight the difficulty of determining the predictability of relationships between IC indicators and economic value (see, Ittner, 2008), and between IC indicators and forecast properties (Mouritsen, 2006; Simpson, 2010). Giuliani and Skoog (2017) add another dimension to IC problematisation, demonstrating IC as a 'temporal boundary object', where composition IC and IC-FC relationships are reflective of a specific time horizon. Hence, for a nuanced understanding of IC, Guthrie et al. (2012, p.79) call for new studies focused on critically examining IC accounting in practice. Research of this genre, to which our study belongs, can narrow the gap between IC theory and practice (Veltri and Bronzetti, 2015). 


\section{Research design}

\subsection{Sample}

We examine initiating coverage analyst reports. Sell-side analysts issue initiating coverage reports whenever their brokerage or investment banking firm commences coverage of a particular company for the first time. Through these reports, analysts seek to brand themselves as company connoisseurs and to signal to their clients their own IC and knowledge. Initiation reports are the lengthiest, most detailed and substantiated type of sell-side reports; they include comprehensive narratives about the company (comprising analysts' reasoning, justifications and arguments) purposefully constructed into a cohesive and convincing investment thesis about the company, aimed at guiding investors' investment decisions. Hence, initiating coverage reports provide ample opportunity for a researcher to study the role of companies' IC in the analysts' practice of sense-making and investment advice. As narratives are essentially sense-making devices (Weick, 1995), we consider the analysis of analyst reports, in which such narratives abound, apt for our purpose. Research methods, such as interviews and participant observation is best for the study of explicit organisational practices as seen in Yu et al. (2017) (i.e., how IC reporting support organisational transformation) and Ahrens and Chapman (2007) (i.e., construction of management control systems), or sense-making that manifests in action, such as Giuliani and Skoog (2017) (i.e., role of time in IC-related management accounting practices). In contrast, essentially (and overtly unobservable) cognitive practices which do not precede action require unobtrusive and non-reactive methods. Interference with the phenomena being investigated can contaminate data, especially when respondents show a tendency to alter their behaviour patterns, respond in a socially desirable manner or attribute more rational thought processes to past decisions (Krippendorff, 2004). On the other hand, Mear and Firth (1987) show that analysts exhibit a high-degree of self-insight, thus rendering their reports suitable devices to be interrogated for purposes such as ours.

Our sample covers 64 initiation coverage reports written by analysts on $S \& P / A S X 300$ companies. We stratify the sample by eight Global Industry Classification System (GICS ${ }^{\circledR}$ ) sectors to represent companies with a varying intensity of reliance on knowledge resources and IC value drivers, and select eight companies per sector and one initiating coverage analyst report per company. We obtain the analyst reports from the OneSource Global Business Browser database, Thomson Analytics database, company websites and analysts directly. The reports in the sample originate from 15 stockbroking or investment banking firms, including 
some of the world's biggest investment houses. The average length of an analyst report is approximately 26 pages.

\subsection{Data analysis}

We read the analyst reports as narratives and analyse them as written texts, using an approach based on narrative theory, commonly termed narrative thematic analysis. The narrative is a way of organising an individual's experiences and memory of events and actions (Bruner, 1991), and it is argued to be the central means through which individuals construct, describe and understand their experiences (McAdams, 1993; Weick, 1995; Weick, 2001) and produce knowledge (Czarniawska, 1998). It operates as an instrument of mind in the (social) construction of reality (Bruner, 1991; Gergen, 1999). Analysts, like most other actors in the capital market, create narratives and tell stories in a professional capacity in their reports to the public (Tuckett and Taffler, 2012). Analysts construct their reports as narratives, as they are "impelled to tell others about something that happened" (e.g., I recommend this company as a buy) and "how it happened" by locating the event(s) that is/are temporally preceding and causally related (e.g., the management of the company changed) (Labov, 2006, p.38). Given the comprehensive nature of initiating coverage reports, we view analysts' narratives as offering meaningful explanations of a company's investment potential, and in that process socially constructing a reality about the analysed company.

Given that narrative is a sense-making device (Weick, 1995), the analysis of analysts' narratives can unravel the socially constructed meanings of IC elements and their roles and relationships. It is a particularly suitable medium for comprehending complexity and ambiguity (Weick and Browning, 1986), such as that surrounding IC (Cuganesan and Dumay, 2009), as narratives establish what connections are, were or might be among events and actions (Maitlis, 2012) of which IC is arguably a part, and configure apparently independent and disconnected elements into related parts of a whole (Martens et al., 2007). Consistent with prior literature, we consider as IC the knowledge possessed by employees (human capital), retained within the organisation (structural capital) and related to the organisation's relationship with external stakeholders (relational capital) (Mouritsen and Roslender, 2009).

We use narrative analysis to identify key themes within and across narratives in relation to how IC is characterised, evaluated and related to other elements of the value-creation story constructed by the analysts (Maitlis, 2012; Riessman, 2008). Although we are the first to apply 
this method to analyst reports, narrative analysis has been used in other capital market contexts, such as investigating storytelling by entrepreneurs in Initial Public Offering prospectuses (Martens et al., 2007) and by fund managers in reports to shareholders (Eshraghi and Taffler, 2015; Jameson, 2000).

\subsubsection{Narrative thematic analysis}

Maitlis (2012, p.493) defines narrative as "a spoken or written text that involves temporal sequences of events and actions". To investigate how the narrator has made sense of a particular phenomenon, one should understand the narrative structure. The narrative structure reveals what is significant and how/why it is significant. A basic narrative includes a breach of the prevailing order due to a precipitating event. Czarniawska (1998, p.2) elaborates this structure as "an original state of affairs, an action or an event and some consequential state of affairs".

The first phase of conducting the narrative thematic analysis was becoming familiar with the data and acquiring a sense of the whole by reading the analyst reports, paying particular attention to the context surrounding the references to IC. Then, we analysed the narratives containing each IC-related reference in terms of: (1) the original state of affairs; (2) the action of event in which IC is implicated; and (3) the consequential state of affairs, as described by Czarniawska (1998). This enabled us to see how the narratives constructed coherent identities (e.g., structural, relational, human or FC, resource or liability), functional properties (e.g., relationships with customers, capabilities of the employees, scale of operations), roles (e.g., highlighting past achievement, inputs to valuation) and relationships (e.g. enhancing FC, contracting FC) of IC.

The second phase involved identification of themes pertaining to the three research questions: (1) What are the identities and properties of IC elements analysts (re)construct and mobilise?

(2) How is relevance of IC elements determined? and (3) How are IC elements related to each other and firm value? This involved one of the co-authors becoming immersed in the narrative surrounding the IC-related references, reading repeatedly and continually moving back and forth between the texts of the entire sample of analyst reports. In this manner, the analyst report narratives were read actively for patterns of relating IC elements to each other as well as to FC, based on the roles and identities that were constructed. Akin to grounded theory, we allowed themes relating to the aforementioned three questions to emerge from and within the dataset. In doing so, IC was used as 'frames' of observation and understanding, enabling some parts of 
the text to be placed in the foreground and others in the background (but not ignored). Exploring the contexts and narratives within which the IC-related references were situated was critical to the analysis, although the emerging themes were later separated from the contexts and grouped together (Maitlis, 2012). We discarded themes considered to be weak, consolidated subthemes into broader themes, and labelled the main themes and subthemes forming our findings pertaining to the three aspects. These broader themes serve as relevant headings to describe the phenomena under investigation and constitute the basis of discussion in this paper.

We use excerpts from analyst reports to clarify links between data and interpretation and for illustrative purposes. The interpretation of the excerpts is reliant on the surrounding narratives, which would be too voluminous to report in the text of this paper. The narratives within which the IC elements occur could span several paragraphs or even several pages.

\section{Findings}

Each of the next three sections explains patterns in sell-side analysts' mobilisation of IC information, organised by the study's research questions.

\subsection{RQ1: Identity and properties of intellectual capital elements}

Our analysis of analysts' narratives shows that the identity and properties of IC elements are temporary, transformative and substitutable.

Analysts do not always attribute to IC elements the properties and identities that are typically associated with them in mainstream (ostensive) IC research and practice. In the eyes of analysts, there are no default properties or identities of IC elements. Analysts mobilise elements of IC in ways that assume properties endemic to other, in some cases quite unrelated, IC elements. One such example is quality and quantity of the workforce. In the practice of IC reporting and measurement, employee-related information encompasses the value-creation potential embedded within firm's human capital. As such, any reference to employees, regardless of the context within which the reference is made, is considered an exemplification of human capital. In contrast, within analyst narratives, references to the quantity of employees of a firm in almost all cases indicates the scale of operation of that firm.

Example 1.1 shown below highlights a reference to the number of employees in an analyst report on Crown Resorts Ltd. The quotation emphasises that Crown Melbourne is "Victoria's 
single-site employer". Also, the paragraph within which this quote is located describes various other attributes that highlight the scale of the company, such as "premier entertainment venue", "one of the largest integrated entertainment facilities in the southern hemisphere"... "16m visitors per annum (300,000 per week)" and "the most visited tourist attraction in Victoria". Thus, the analyst is mobilising employee numbers not to highlight the firm's human capital capability but rather its structural capital in the form of the firm's scale of operation, which links to organisational competence. This example demonstrates that an element of human capital (e.g., the number of employees) loses the property typically ascribed to it in IC research and gains the property of another type of IC - in this case, structural capital. However, the transformation is temporary, as IC elements may revert to their supposedly default forms when the analyst mobilises them in such ways.

\section{Example 1.1: Transformation of human capital into structural capital}

Crown Melbourne is Victoria's largest single-site employer, with 7,000 employees, $-5,600$ of which are directly employed and the remainder employed within the complex by suppliers of services. (Analyst report on Crown Limited)

The analyst report extract provided in Example 1.2 below appeared on the first page of the analyst report on Babcock \& Brown Limited, a fund management firm.

\section{Example 1.2: Transformation of structural capital into relational capital}

Founded in the United States in 1977, Babcock \& Brown (BNB) is a global investment and advisory firm with longstanding capabilities in structured finance, syndication and investment management. (Analyst report on Babcock \& Brown Limited)

After analysing the larger narrative within which this extract is positioned, it is evident that the purpose of drawing on the firm's size (i.e., global reach) and capabilities is to portray the firm as reputable. An approach commonly adopted in analyst reports is setting the scene for a detailed discussion of firms' IC stock by first evaluating the firm's image and reputation. Thus, interpretation of Example 1.2 should happen within the broader context of the narrative, which extends over multiple pages. The example implies the construction of one IC element (i.e., company image and reputation) by drawing upon and transforming other IC elements (i.e., the scale of operations and organisational competencies), each with its own unrelated properties. Examples of other elements of IC that were drawn together in a similar fashion to construct a new IC element include market power, innovativeness, track-record and uniqueness. 
Not only elements of IC but also FC are transformed into IC. For instance, in the analyst report on Perpetual Limited, as shown in Example 1.3, changes in FC in the form of the growth in funds under management and greater investment returns are mobilised to build a favourable image of the company. While FC is a consequence of successful utilisation of IC, in this instance, FC is appears to assume the properties of a relational capital element (corporate image and reputation).

\section{Example 1.3 Transformation of financial capital into relational capital}

The BIAM team is well-known to prospective offshore clients and has a strong record of FUM (funds under management) growth and performance through investment returns under the former owners. (Analyst report on Perpetual Limited)

Substitutability of IC elements is a feature inconsistent with the tenets of contemporary IC accounting. Underpinned by the economic notion of capital, the contemporary practice of IC accounting drives firms to accumulate and enhance IC under the assumption that all kinds of IC are value-relevant (Mouritsen, 2006). This perspective favours the use of IC taxonomies to track firm progress in enhancing all elements of IC. There is no appreciation of trade-offs between IC elements. However, analysts do not view IC in this manner. They demonstrate that firm value can be enhanced by substituting one form of IC for another.

\subsection{RQ2: Determining relevance or irrelevance of intellectual capital}

We recognise three main methods of determining the relevance (or importance) of IC elements through our narrative analysis. They are based on IC's (1) usefulness for determining valuation parameters; (2) role in justifying stock recommendations; and (3) position within the valuecreation story.

In the first method, the relevance of an IC element depends on whether it has an association with valuation parameters used in valuation models (e.g., discounted cash flow models and earnings multiples models). IC elements that cannot be related to valuation parameters can still be considered relevant if they can be used in justifying stock recommendations. This is because stock recommendations do not always flow directly from analysts' valuations, and additional IC elements go into justifying stock recommendations. Some of the less quantifiable and longterm IC value drivers are assigned relevance according to this second method. Both these methods invoke an ostensive conceptualisation of IC - they assume stability in descriptive qualities of IC elements, consider past relevance as a predictor of future relevance and ascribe 
relevance based on IC's relationship to financial risks and returns. Prior research has explained the relevance of IC with reference to these two methods (e.g., Abhayawansa et al., 2015).

What is novel in this paper is the finding that analysts also attribute relevance to IC items that are not typically associated with valuation parameters and stock recommendations, and cannot be measured in the form of indicators. In this light, studies such as Flöstrand (2006) and Nielsen (2004) have fallen short of proving a holistic explanation of what IC is relevant and why. However, analysts do not see all IC items typically described as relevant by firms as important in assessing firm value either. We find that IC elements may be considered relevant or not based on their position within the value-creation story narrated by the analysts. This third method of understanding the relevance of IC elements highlights the performativity of IC as it draws on IC's situated and contingent nature.

Within the value-creation story, various elements of relational capital (e.g., the power of the firm's brands, its overall and brand market share, strength of customer relationships, distribution network and bargaining power, favourable contracts, and relationships with financial institutions, government and other stakeholders) and, to a lesser extent, structural capital (e.g., corporate culture, information technology and information systems, management processes, organisational and business expertise, management structure and research and development capabilities) gets evaluated. This evaluation and, as a result, the inclusion of IC elements within analysts' narratives on value creation, typically occurs within at least four thematic contexts. They are (1) assessing an IC element's impact on past financial performance or the performance of other IC elements; (2) alignment of an IC element with firms' strategy, business model and industry competition; (3) an IC element's ability to overcome risks and capitalise on opportunities emanating from the business' external and internal environments; and (4) an IC element's position within a collective of other IC elements. Each of these themes highlights that relevance of IC is (temporarily) contingent on the situation in which it is mobilised and the various other parameters that coexist in that situation. Thus, there is no stability in descriptive qualities of IC elements, and past relevance is not a predictor of future relevance. This performative conceptualisation of IC is teased out in the following discussion of the four themes.

\subsubsection{Impact on past performance/IC}

The importance of IC elements for future value creation is sometimes demonstrated by referring to their past performance in terms of enhancing other IC and FC or overcoming 
deficiencies in developing FC. Elements of relational capital (brands and business collaboration, such as acquisitions and joint ventures), structural capital (business model and organisational and business expertise) and top management human capital are frequently referred in the narratives for their role in creating FC. When attributing relevance to IC in this manner, analysts appreciate the context of the firm's operations, including its IC, FC and strategy at the time. Thus, we see that the relevance of IC elements is contingent on the extent to which the past context is expected to manifest in the future. Analysts' appreciation of IC for its ability to accomplish something and IC's situated nature highlights the performativity of IC. In Example 2.1, the extract from an analyst report on Valad Property Group characterises the company's management team as relevant IC, as it had been able to overcome challenges in the past. However, they also highlight that the management team was able to do so due to the coexistence of a conducive capital structure. Given that this capital structure still exists in the company, analysts do not expect the expertise of the management team to be any less relevant in increasing firm value in the future. Moreover, the analysts see the future relevance of the management team intensifying due to its ability to manage leasing risks and source alternative income streams. Our analysis, however, shows that analysts appreciate the temporal nature of IC effects and acknowledge that successful past performances of IC may not necessarily be repeated in the future in a constantly changing environment.

\section{Example 2.1: Past success of the firm's IC}

The combination of a capable and adaptable management team working within the optimal capital structure for a diversified property vehicle (stapled) has seen a number of challenges overcome. Active management of leasing risk and the ability to source alternative income streams (e.g. development profits, self-storage property) reinforces our confidence in Management's ability to maximise returns throughout all stages of the property cycle. (Analyst report on Valad Property Group)

\subsubsection{Alignment with firm's strategy, industry and competition}

The IC elements that are mobilised and made significant within the value-creation story are contingent on firms' strategies, which depend on firms' industry and competition. Analysts narrate value-creation stories from their perspective through discussions of firm strategy. The analysts' perceived strategy of the firm shapes their investment thesis (or plot of the story) and becomes the thread that weaves IC elements together. The firm strategy can be one or more of increasing revenue, reducing costs or pursuing acquisitions. The analyst report on Ramsey 
Healthcare Limited (RHC), one of the largest private hospital operators in Australia, is a good example of how relational capital elements become relevant to the analysts' investment thesis due to the nexus between relational capital and firm strategy. The relevant extracts from the analyst report on RHC are provided in Example 2.2. This example shows that RHC's relationship with doctors (i.e., relational capital) is critical to achieving its strategy of attracting more patients to its hospitals. The report also highlights how human capital (i.e., capabilities of the management) and structural capital (i.e., human resource policies and administrative systems) gain relevance for their supportive role in leveraging the benefits from relational capital, given the firm's strategy.

\section{Example 2.2: Linking strategy and IC elements}

In 2006, RHC management proposed to spend up to A $\$ 400 \mathrm{~m}$ to further develop large multi-service hospitals to attract increased referrals in major metropolitan areas. We believe the strategic rationale behind this proposal is to provide upgrades to ensure the ongoing use of RHC hospitals by higher-margin specialists. In our view, doctors are the major internal stakeholders who ensure high admission rates for a private hospital. ... Our contacts have said that RHC management is very good at ensuring a constant work environment for its doctors by ensuring adequate and stable staffing, and reasonably flexible admission policies for the doctors' patients. (Analyst report on Ramsay Health Care Limited)

\subsubsection{Importance based on the ability to mediate risks and opportunities}

Analysts' recommendations on firms are based on their perception of firms' ability to take advantage of opportunities and overcome threats in the macro and competitive environment. Based on analysts' macro and micro environmental analysis, three possible sources of opportunities are identified - external environment, IC and FC. The importance of IC elements is established in line with the nature of the opportunity. The first quote in Example 2.4 highlights an opportunity arising from industry- or market-level changes in the external environment. The opportunity enables the analysts to legitimise IC (i.e. supply chain systems) for their potential to create value. Figure 1, found in the analyst report on Billabong Limited and shown in Example 2.4 (b), highlights how the company's existing IC (i.e., brand image) can create opportunities to introduce new products that can further strengthen the brand. Arguably, the IC elements that had become important in the two cases shown in the example would not have otherwise been considered important if not for the aligned opportunities. 
(a) ...the industry is currently fragmented, providing an opportunity for WOW to use its buying power and superior supply chain systems to grow market share. (Analyst report on Woolworths Limited)

(b) A table showing brand extension opportunities

\section{Figure 1}

Extract from the analyst report on Billabong Limited.

\begin{tabular}{|l|l|l|l|l|l|}
\hline Brand & $\begin{array}{l}\text { Apparel } \\
\text { mens }\end{array}$ & $\begin{array}{l}\text { Apparel } \\
\text { womens }\end{array}$ & Footwear & Accessories & Snow \\
\hline Billabong & Existing & Existing & Opportunity & Existing & Existing \\
\hline Element & Existing & & Opportunity & Opportunity & Opportunity \\
\hline Von Zipper & Existing & Opportunity & & Existing & Opportunity \\
\hline Honolua & Existing & Opportunity & Opportunity & Opportunity & \\
\hline Kustom & Opportunity & & Existing & & Opportunity \\
\hline Palmers & Opportunity & & & Existing & \\
\hline
\end{tabular}

(Analyst report on Billabong Limited)

Sometimes, IC elements gain relevance in the eyes of analysts when they enable firms to overcome threats/risks or mitigate weaknesses. In Example 2.5, IC elements such as organisational policies and processes that are aligned with industry best practices and protocols are important because they enable the company to address the specific risks it faces.

\section{Example 2.5: Overcoming threats/risks through IC}

The horticultural and timber projects are subject to seasonal and climatic risks. ... TIM minimises these risks where possible by engaging leading industry contractors, adopting industry best practices and protocols, arranging appropriate insurance cover and, in the case of its horticultural and viticultural operations, by acquiring sufficient permanent water licences to irrigate the estates, and by installing the most advanced irrigation infrastructure. (Analyst report on Timbercorp Limited)

The relevance of IC elements is driven by their ability to create or enable the firm to exploit opportunities or mitigate threats. Our analysis highlights that analysts use IC in mediating between opportunities/threats. Analysts ignore IC elements that are only useful in maintaining the status quo.

\subsubsection{Importance dependent on collective mobilisation}

Some IC elements are not meaningful and, therefore, not relevant individually, but become so when combined with other IC elements. One example of this is human capital information 
about firms' senior management. Analysts dedicate considerable space in their reports to comment on the human capital associated with the senior management of the firm. Aspects such as the educational and professional qualifications, memberships of professional bodies, directorships of other entities, skills, capabilities, and years and nature of prior work experience of important senior management personnel are described therein. For instance, Example 2.6 shows that two separate human capital elements, reputation and work experience of the firm's top management, are not utilised individually but collectively to create a composite measure of management quality. In their investment theses analysts rely on what they call "management's demonstrated ability to add value in trying times" to justify their confidence in the firm's longterm performance. Analysts have drawn on various elements of top management human capital to develop this new human capital construct. While these specific human capital elements become relevant in the present situation, they have not come together to create the same meaning in other firms analysed or even different situations of the same firm. This explains that even the collective mobilisation of IC elements is context-dependent.

\section{Example 2.6: Human capital elements about senior management}

Two of the original founders of VPG, Stephen Day (Executive Chairman) and Peter Hurley (Managing Director), are still involved in managing the Group's operations and strategic direction. Co-founder Barry Wynne stepped down as Chairman ... to act as a consultant on major projects. All three executives are highly regarded in the Sydney property market and previously have extensive experience with Lend Lease Corporation. (Analyst report on Valad Property Group)

\subsection{RQ3: Relationship between intellectual capital and firm value}

Analysts' narratives demonstrate two main ways in which analysts comprehend the relationship between a given IC element and firm value: (1) direct, linear relationship; and (2) complex, non-linear or open-ended relationship whose form, nature and intensity are contingent. The first is founded on a predominantly ostensive approach to IC while the second is a manifestation of defining IC as a performative phenomenon. Nonetheless, even in the first type of relationship the nature and direction of causality can be case-specific and temporally contingent, exemplifying IC as performative. The ostensive and performative attributes embedded in the two types of relationships are explored below. 


\subsubsection{Direct relationships}

Analysts demonstrate that some IC elements contribute directly, in an almost linear fashion, to increasing (and sometimes decreasing) firm value. This suggests a predictive model of IC in the eyes of analysts, where relationships between IC and firm value are determinable, causal and sequential. Analysts incorporate IC elements that are considered key value drivers into estimates of financial and non-financial variables in their valuation models. In Example 3.1, analysts explicitly link the positive effect of the firm's new brands (i.e., relational capital) to double-digit growth in profits. Mostly, relational and structural capital elements are attributed to firm value in this manner.

\section{Example 3.1: Attribution of IC elements to financial variables}

We forecast BBG will deliver a net profit of $\$ 144.0$ million, growth of $15 \%$ for FY06e. We forecast strong double-digit profit growth for the next five years as BBG's newer brands increase distribution penetration and new product lines are launched. ... New brands will help double sales over the next five years. ... These newer brands will leverage BBG's distribution and product development expertise. (Analyst report on Billabong International Limited).

In some cases, analysts avoid assuming the quantified impact of IC elements on firm value through profits but estimate a premium relative to, for example, price/earnings multiples to take account of IC. Example 3.2 shows that analysts' perceptions of the firm's relational capital (i.e., market position) become one of the two determinants of the magnitude of the multiplier. This approach allows analysts freedom to take account of human capital as well as other elements of IC, the impact of which is not always intelligible.

\section{Example 3.2: Attribution of IC elements to valuation multipliers}

We estimate the implied multiples of domestic casino assets are -10.0-11.0x and we value Crown's businesses at the upper end of this range given the strong forecast earnings growth of Burswood and the strong market position of Crown Melbourne. (Analyst report on Crown Limited)

The existence of direct relationships between IC and firm value indicates a generalised model of IC, supporting the ostensive view of IC. However, although analysts understand that causal links exist, the above observations also highlight the difficulty of envisaging how the specific impacts of IC elements translate into valuation parameters. The difficulty of explaining this translation process might be attributed to the fact that IC is performative - IC has many possible 
futures whose nature and potency will depend on the context of its mobilisation. Hence, analysts leave the links forged between IC and firm value open for alternative interpretation.

\subsubsection{Complex relationships}

Some IC elements are attributed to firm value indirectly via various interrelationships established with other IC elements and tangible capital. In doing so, analysts demonstrate the complexity and fluidity of the relationships among elements of IC that ultimately determine firm value. These observations challenge the ostensive notion of IC, which depicts IC as having linear and sequential relationships to other IC and firm value. Due to their training in viewing IC from a firm valuation perspective, analysts offer unique perspectives on the interrelationships between IC and firm value that are absent from corporate narratives. These perspectives highlight how IC relations are continuously discovered in different episodes of practice. Example 3.4 provides types of complex IC relationships explicated by analysts. The first quote highlights the nexus between management processes, policies and distribution platforms (structural capital), and supplier and customer relationships (relational capital), which will ultimately lead to higher revenue and lower costs. The second quote explains how investing in one type of relational capital (i.e., relationship with regulatory stakeholders) has a cascading effect on building more of the same and other relational capital elements (i.e., networks).

\section{Example 3.4: Interrelationships between IC elements}

(a) Priceline stores and Priceline Pharmacies being the only health and beauty product stores that have compliant store layouts [sic]. In other words, a Maybelline display will be the same in all 150 Priceline stores and 124 Priceline Pharmacies. This capability is attractive to both API's suppliers and customers. ... The suppliers have been encouraged by API's store layout compliance and its growth. ... API's retail division model is based on Shoppers Drugmart in Canada. Shoppers Drugmart achieved a 110 basis point reduction in its cost of goods line in 1H07 (expressed as a percentage of sales). Buying power was a contributing factor. In addition, API intends to adopt some of the supply chain efficiencies that Shoppers Drugmart has achieved in the longer term such as reducing its distribution centre numbers and store deliveries rounds. Consequently, these factors have contributed to API receiving favourable supply contracts including substantial rebates from suppliers. (Analyst report on Australian Pharmaceutical Industries Limited) 
(b) Through its relationship and dialogue with the regulator, Inexus has consistently managed to establish a favourable regulatory environment that continues to encourage the development of new networks. (Analyst report on Challenger Infrastructure Fund)

According to the ostensive approach, while IC affects firms' financial position (or FC), the reverse impact of FC on IC is not expected. However, we document evidence of the latter in analysts' practice. For instance, analysts demonstrate that company investment (divestment) decisions result in enhancements (reductions) in IC elements, leading to further increases (decreases) of firm's FC. An analyst report on CSL Limited provides a good example of this type of FC-IC-FC relationship. The report explains that CSL's strong financial position has supported it to make acquisitions, enabling it to grow operations. The resultant enhanced scale of operations (i.e., a structural capital element) and stronger market position (i.e., a relational capital element) are expected to further increase FC by enabling the company to charge higher prices. Although a single quote from the CSL's analyst report cannot demonstrate this entire narrative, Example 3.5 summarises it.

\section{Example: 3.5: Reciprocal relationship between FC and IC}

The $\mathrm{AB}$ acquisition has turned CSL into a global player in the plasma products business, and CSL now has the scope to use its position to help set prices for IVIG. (Analyst report on CSL Limited)

\section{Discussion and conclusion}

\subsection{In support of a performative view of IC}

Our findings challenge the ostensive view of IC, which assumes each IC element to have static identities and functional properties and be a value-generating asset (see, Mouritsen, 2006). According to our findings, analysts consider IC elements as having variable properties. We observe that when analysts mobilise IC in their narratives, some IC elements are transformed out of the arguably 'default' functional properties ascribed to them in ostensive research and made to assume identities and functional properties normally ascribed to other IC elements. Analysts comprehend identities of IC elements as interchangeable and, as a result, substitutable. These observations about IC support Mouritsen's (2006) conceptualisation of IC as a boundary object. A boundary object "has an appearance that allows us to see it, but it is impossible to predict its effects from these properties since they are weakly structured" (Mouritsen, 2006, p.826). Consistent with the notion of a boundary object, we find that analysts do not assume identities and properties of IC a priori but ascribe particular identities and roles 
to IC elements depending on their association with other entities. The identity and role of an IC element need to be determined in relation to what it has been mobilised to perform within the analysts' narratives. These findings question the (ostensive) view that IC elements are known entities in the form of human, structural and relational capital, and their properties are independent of any interactions that actors initiate. IC measurement initiatives and preparation of IC statements are based on this view, which is restrictive at most and flawed at best. Any attempt to measure IC first involves compartmentalising IC elements based on taxonomies and, second, measuring their development in relation to only one, a priori known manifestation of each IC element's properties. This ignores IC's dynamic properties and draws a unidimensional view of various organisational IC.

Analysts do not consider every IC element to be a value-generating asset either. The 'default' functional properties of some IC elements are never invoked in building firms' value-creating stories, indicating that those IC elements are either not important enough to be mobilised or merely there to maintain the status quo. Moreover, some IC elements are considered intellectual liabilities or value destroyers. Such IC elements are shown to have lost (or be likely to lose) their competitive advantage or even be considered a hindrance to the firm. This is evident through analysts' appreciation of firms' decision to substitute IC elements when the substituting IC element is capable of generating more FC than the substituted IC element. The dynamic effects of IC enable value-generating IC elements in one context to transform into intellectual liabilities in another. In this manner, the 'dark sides' of IC and intellectual liabilities not generally accounted for by organisations (Gowthorpe, 2009) are made visible through analysts' practice.

We find that IC elements are attributed to firm value both directly, in a linear manner (consistent with the ostensive view of IC), and indirectly, via various non-linear interrelationships established with other IC elements, tangible capital and FC (interpretable through a performative view of IC). Our findings show that while the effects of some IC can be related to organisational outcomes and more or less precisely quantified, such instances are in the minority. From an ostensive standpoint, one can only predict the importance of an IC element to organisational success or the magnitude of its impact on firm value if IC elements are connected to value creation and/or organisational outcomes in one fundamental way. More often, analysts do not adopt a predictive model of IC, as in assuming future relations to be a replication of past relations. While explaining IC achievements is important for analysts as a means of establishing value-relevant IC elements, they assess the external context and changes 
in IC and organisational activities before making predictions based on past IC relationships. This is symptomatic of valuing according to the performative view of IC as described by Mouritsen (2006). He states that in a performative view of IC, "the past is important because this is where capability and knowledge are created but it is also something that has to be reappraised in order to be a resource for the future" (Mouritsen, 2006, p.834).

Our results indicate a new notion of value-relevance for IC that does not depend on the causal relationships between IC elements and financial variables. We see that analysts bestow valuerelevance to IC elements in their narratives based on their position within the business model, alignment with the firm's strategy and product market competition, ability to generate and capitalise on opportunities and mitigate threats, and association to other IC elements that can be mobilised as a collective. In other words, within the analysts' narratives, IC elements find their meaning and importance in each situation in association with other entities that exist in that situation. Viewing value-relevance in situ, where the roles of IC elements change depending on firms' circumstances, is founded in the performative view of IC (Mouritsen, 2006). Since "the influence of IC depends on how it is represented in the first place" (Mouritsen, 2006, p.826), understanding the nature of value-relevance of IC in situ requires an appreciation of the narratives within which IC elements are given meaning. Similar to how one employee's account of an IC element's effect on the organisation differs from another's (Roslender and Fincham, 2001), different analysts create different narratives from the same events (and IC elements). Several possible futures can exist for a given IC element as analysts mobilise it in different ways within their narratives. Hence, it is through a situated model of IC that IC elements' value-relevance can be determined, not through a predictive model. The causal mapping techniques developed by scholars such as Marr et al. (2004), Roos et al. (2005) and Montemari and Nielsen (2013) might find utility in making intelligible some of the possible futures of IC elements and complex relationships. However, these maps do not model the future. They are inherently past-oriented, owing to their origins in the ostensive view of IC.

We shed light on the complexity of the relationships between IC and FC. The manners in which analysts have linked IC and FC demonstrate the importance of applying ostensive as well as performative views of IC to the understanding of IC. Consistent with the ostensive view and akin to the IC relationships demonstrated from an organisational perspective (e.g., Hermans and Kauranen, 2005; Jhunjhunwala, 2009; Youndt et al., 2004), analysts in our study directly relate IC elements to FC in a linear manner, with human capital, structural capital and relational capital connected to each other or FC in various linear combinations. Nonetheless, they also 
view IC through a performative lens, comprehending it as a nexus of relationships whose ultimate impact on FC is contingent on other entities or the particular situation. In this regard, using a case study of a firm investing in IC shows that the nexus between an IC element and FC may not only be mediated by other IC elements but also by tangible capital and aspects of FC, suggesting indirect and complex relationships. Our findings add to the current understanding of these complex relationships. First, we show that IC mediates the linkages between external opportunities/threats and FC, and external opportunities become legitimate options in the face of enabling IC elements. Second, IC builds upon itself in an almost cascading manner, resulting in more potent impact on FC. Third, negative relationships exist between IC elements due to substitutionary effects. For instance, when the relationship with FC becomes negative for one IC element (e.g., employees), it becomes positive for another IC element (e.g. automated systems and processes). Fourth, FC can transform into (rather than create) IC. We revisit this fourth aspect in the following paragraphs. Finally, and most importantly, our results highlight the difficulty of even envisaging the nature of IC-FC relationships in some instances. We see the relationship between IC and FC as so loosely coupled, resulting in numerous possible links, that analysts leave the interpretation of possible IC and FC futures to the readers of analyst reports. These findings highlight the need to adopt a performative view for a better comprehension of IC.

This study enables us to gain a better understanding of FC in relation to IC. In particular, we find that FC too embodies dynamic properties when analysts build a value-creation story of the company. Murthy and Mouritsen (2011, p.644) identified that "financial capital turns out to be input when it is a deconstructed budget, while it is an output when it is a comprehensive calculation of shareholder value". We extend this problematisation and the conceptualisation of FC in IC research. Our results show that FC is not only an effect of and input to IC but also a legitimiser of IC and sometimes a manifestation of IC itself. For instance, to a potential investor, FC, in the form of shareholder value, carries a message about its reputation (relational capital) or management quality (human capital) or even overall quality of firms' IC bundles, legitimising its value-creation potential. It is with this knowledge of FC that we should revisit Mouritsen's (2003) contention that IC sometimes appears to be invisible in analysts' communications because it is translated into a financial form and presented using financial language. 


\subsection{Implications}

Our observations have implications for contemporary reporting practice and policy initiatives. Much prior research has been concerned with what IC to include within the existing reporting model. Consequently, substantial work is being done predicated on the notion that increased reporting of IC is required to meet the (previously unmet) information needs of investors and other stakeholders, allow assessments of long-term organisational viability and facilitate effective decision-making (Holland, 2004; MERITUM, 2002). Our results indicate that the process and format of reporting IC are not only dogged by conceptual and measurement uncertainties highlighted by Gowthorpe (2009), but are also unable to elucidate the situated form, function and value of organisational IC. The ostensive IC reporting model is not flexible enough to accommodate the nebulous and complex facets of IC revealed in this study (Gowthorpe, 2009). Therefore, IC reporting is criticised from an informational efficiency point of view. The challenge for IC research is not to seek a better IC reporting model, which has been its predilection for the past one and half decades, but to find mechanisms to situate IC narratives within the organisational and broader environmental contexts and history. Contemporary integrated and strategic reporting initiatives can be viewed as steps in this direction. However, they do not go far enough: as Nielsen and Madsen (2009, p.853) argue, understanding corporate IC and value creation is gained through a "process encompassing many different information channels" and by "following the company over a longer period of time", an argument consistent with our observations.

Our results highlight that determining the importance of IC information from a capital market's perspective using research methods grounded in the ostensive view of IC is problematic. Not only is it impossible to predict the future importance of IC elements based on their past performance, but IC's importance is also situated in "all manner of localities, circumstances, and contingencies that cannot be generalised" (Mouritsen, 2006, p.836). Thus, capital markets based archival research, surveys with capital market actors or content analysis based studies that proxy importance with frequency are unlikely to provide an adequate understanding of what, how and when IC elements are important for a company. Much prior research has adopted these methods to identify IC elements likely to be (more) important to investors with the noble aim of enhancing the relevance of corporate IC reporting (Holland, 2004). Based on our findings, we argue that not only are the research methods problematic in relation to their aim but the aim itself is untenable. We show in this paper that understanding IC importance is 
achieved through the careful study of narratives produced by capital market actors. By observing how analysts locate IC elements within their narratives - whether they are in or out of the plot, and in the foreground or the background - and the simultaneity of their mobilisation with other entities in the value-creation story, it is possible to see IC's role in the construction of claims about firm value. However, what we understand is only one of the possible versions of the importance of IC of the given company at a given point in time.

Also, IC reporting initiatives assume that the 'information problem' is primarily located on the 'supply-side' (Nielsen and Madsen, 2009), and that actors such as sell-side analysts are pure intermediaries, rather than producers of narratives about a firm's IC and its value, with their own interests in mobilising IC information in particular ways, as we observe in this study. Thus, greater investigation and consideration of 'demand-side' actors, how their narratives of firm value might be transformed by increased reporting of forward-looking and contextualised information from companies, and how these different narratives compete with or complement each other in decision-making and action by prospective investors are important areas for future research. 


\section{References}

Abhayawansa, S., Aleksanyan, M. and Bahtsevanoglou, J. (2015), "The use of intellectual capital information by sell-side analysts in company valuation", Accounting \& Business Research, Vol. 51 No. 5, pp. 279-306.

Abhayawansa, S. and Guthrie, J. (2012), "Intellectual capital information and stock recommendations: Impression management?", Journal of Intellectual Capital, Vol. 13 No. 3, pp. 398-415.

Ahrens, T. and Chapman, C. S. (2007), "Management accounting as practice", Accounting, Organizations and Society, Vol. 32 No. 1-2, pp. 1-27.

Anderson, E. W., Fornell, C. and Rust, R. T. (1997), "Customer satisfaction, productivity, and profitability: differences between goods and services", Marketing Science, Vol. 16 No. 2, pp. 129-145.

Andreeva, T. and Garanina, T. (2016), "Do all elements of intellectual capital matter for organizational performance? Evidence from Russian context", Journal of Intellectual Capital, Vol. 17 No. 2, pp. 397-412.

Bontis, N. (1998), "Intellectual capital: an exploratory study that develops measures and models", Management Decision, Vol. 36 No. 2, pp. 63-76.

Bontis, N. and Fitz- enz, J. (2002), "Intellectual capital ROI: A causal map of human capital antecedents and consequents", Journal of Intellectual Capital, Vol. 3 No. 3, pp. 223247.

Bowker, G. C. and Star, S. L. (1999), Sorting Things Out: Classification and its Consequences, MIT Press, USA.

Bruner, J. (1991), "The Narrative Construction of Reality", Critical Inquiry, Vol. 18 No. 1, pp. $1-21$.

Bueno, E., Salmador, M. P., Rodríguez, Ó. and De Castro, G. M. (2006), "Internal logic of intellectual capital: a biological approach", Journal of Intellectual Capital, Vol. 7 No. 3, pp. $394-405$.

Catasus, B., Ersson, S. and Wallentin, F. (2007), "What gets measured gets ... - on indicating, mobilizing and acting", Accounting, Auditing \& Accountability Journal, Vol. 20 No. 2, pp. 505-521.

Chua, W. F. (1986), "Radical developments in accounting thought", The Accounting Review, Vol. 61 No. 4, pp. 601-632.

Cuganesan, S. (2005), "Intellectual capital-in-action and value creation: a case study of knowledge transformations in an innovation project", Journal of Intellectual Capital, Vol. 6 No. 3, pp. 357-373. 
Cuganesan, S. and Dumay, J. C. (2009), "Reflecting on the production of intellectual capital visualisations", Accounting, Auditing \& Accountability Journal, Vol. 22 No. 8, pp. 1161 - 1186.

Czarniawska, B. (1998), A Narrative Approach to Organisational Studies, Thousand Oaks, CA.

Damodaran, A. (2008), Damodaran on valuation, John Wiley \& Sons, Hoboken, New Jersey.

Dumay, J. (2014), "15 years of the Journal of Intellectual Capital and counting: A manifesto for transformational IC research", Journal of Intellectual Capital, Vol. 15 No. 1, pp. 2 37.

Dumay, J. C. (2009), "Intellectual capital measurement: a critical approach", Journal of Intellectual Capital, Vol. 10 No. 2, pp. 190-210.

Dumay, J. C. (2012), "Grand theories as barriers to using IC concepts", Journal of Intellectual Capital, Vol. 13 No. 1, pp. 4-15.

Eshraghi, A. and Taffler, R. (2015), "Heroes and victims: fund manager sensemaking, selflegitimation and storytelling", Accounting and Business Research, Vol. 45 No. 6-7, pp. 691-714.

Flöstrand, P. (2006), "The sell side - observations on intellectual capital indicators", Journal of Intellectual Capital, Vol. 7 No. 4, pp. 457-473.

García-Meca, E. and Martínez, I. (2007), "The use of intellectual capital information in investment decisions: An empirical study using analyst reports", International Journal of Accounting, Vol. 42 No. 1, pp. 57-81.

Gergen, K. J. (1999), An Invitation to Social Construction, Sage, Thousand Oaks.

Giuliani, M. and Skoog, M. (2017), "Making sense of the temporal dimension of intellectual capital: A critical case study", Critical Perspectives on Accounting, DOI: doi.org/10.1016/j.cpa.2017.04.001.

Gowthorpe, C. (2009), "Wider still and wider? A critical discussion of intellectual capital recognition, measurement and control in a boundary theoretical context", Critical Perspectives on Accounting, Vol. 20 No. 7, pp. 823-834.

Guthrie, J., Ricceri, F. and Dumay, J. (2012), "Reflections and projections: A decade of Intellectual Capital Accounting Research", The British Accounting Review, Vol. 44 No. 2, pp. 68-82.

Hermans, R. and Kauranen, I. (2005), "Value creation potential of intellectual capital in biotechnology - empirical evidence from Finland", $R \& D$ Management, Vol. 35 No. 2 , pp. 171-185.

Holland, J. (2004), Corporate intangibles, value relevance and disclosure content (Institute of Chartered Accountants of Scotland: Edinburgh). 
Huang, C. J. and Liu, C. J. (2005), "Exploration for the relationship between innovation, IT and performance", Journal of Intellectual Capital, Vol. 6 No. 2, pp. 237 - 252.

Ittner, C. D. (2008), "Does measuring intangibles for management purposes improve performance? A review of the evidence", Accounting and Business Research, Vol. 38 No. 3, pp. 261-272.

Jameson, D. A. (2000), "Telling the Investment Story: A Narrative Analysis of Shareholder Reports", Journal of Business Communication, Vol. 37 No. 1, pp. 7-38.

Jhunjhunwala, S. (2009), "Monitoring and measuring intangibles using value maps: some examples", Journal of Intellectual Capital, Vol. 10 No. 2, pp. 211 - 223.

Kallapur, S. and Kwan, S. Y. S. (2004), "The value relevance and reliability of brand assets recognized by U.K. firms", The Accounting Review, Vol. 79 No. 1, pp. 151-172.

Krippendorff, K. (2004), Content analysis - An introduction to its methodology, Sage Publication, Inc., California.

Labov, W. (2006), "Narrative pre-construction", Narrative Inquiry, Vol. 16 No. 1, pp. 37-45.

Latour, B. (1986), "The powers of association", in J. Law (Ed.), Power, actions and belief: A new sociology of knowledge, Routledge and Kegan Paul, London, pp. 264-280.

Maitlis, S. (2012), "Narrative analysis", in G. Symon \& K. Cassell (Eds.), Qualitative Organisational Research: Core Methods and Current Challenges,Sage, London, pp. 492-511.

Marr, B., Schiuma, G. and Neely, A. (2004), "The dynamics of value creation: mapping your intellectual performance drivers", Journal of Intellectual Capital, Vol. 5 No. 2, pp. 312325.

Martens, M. L., Jennings, J. E. and Jennings, P. D. (2007), "Do the stories they tell get them the money they need? The role of entrepreneurial narratives in resource acquisition", The Academy of Management Journal, Vol. 50 No. 5, pp. 1107-1132.

Martín-de-Castro, G., Delgado-Verde, M., López-Sáez, P. and Navas-López, J. E. (2011), "Towards 'An Intellectual Capital-Based View of the Firm': Origins and Nature", Journal of Business Ethics, Vol. 98 No. 4, pp. 649-662.

McAdams, D. P. (1993), The Stories We Live By: Personal Myths and the Making of The Self, William Morrow and Co., New York.

Mear, R. and Firth, M. (1987), "Cue usage and self-insight of financial analysts", The Accounting Review, Vol. 62 No. 1, pp. 176-182.

MERITUM (2002), Measuring intangibles to understand and improve innovation management (European Commission: Brussels).

Montemari, M. and Nielsen, C. (2013), "The role of causal maps in intellectual capital measurement and management", Journal of Intellectual Capital, Vol. 14 No. 4, pp. $522-$ 546. 
Mouritsen, J. (2003), "Intellectual capital and the capital market: the circulability of intellectual capital", Accounting, Auditing and Accountability Journal, Vol. 16 No. 1, pp. 18-30.

Mouritsen, J. (2006), "Problematising intellectual capital research: ostensive versus performative IC", Accounting, Auditing \& Accountability Journal, Vol. 19 No. 6, pp. 820-841.

Mouritsen, J. and Koleva, G. (2004), "The actorhood of organisational capital", International Journal of Learning and Intellectual Capital, Vol. 1 No. 2, pp. 177 - 189.

Mouritsen, J. and Roslender, R. (2009), "Critical intellectual capital", Critical Perspectives on Accounting, Vol. 20 No. 7, pp. 801-803.

Murthy, V. and Mouritsen, J. (2011), "The performance of intellectual capital: Mobilising relationships between intellectual and financial capital in a bank", Accounting, Auditing \& Accountability Journal, Vol. 24 No. 5, pp. 622-646.

Namasivayam, K. and Denizci, B. (2006), "Human capital in service organizations: identifying value drivers", Journal of Intellectual Capital, Vol. 7 No. 3, pp. 381 - 393.

Nielsen, A. C. (2004), Through the eyes of analysts: A content analysis of analyst report narratives, Working Paper (Aarhus School of Business: Aarhus).

Nielsen, A. C. and Madsen, M. T. (2009), "Discourses of transparency in the intellectual capital reporting debate: Moving from generic reporting models to management defined information", Critical Perspectives on Accounting, Vol. 20 No. 7, pp. 847-854.

O'Donnell, D., Henriksen, L. B. and Voelpel, S. C. (2006), "Guest editorial: Becoming critical on intellectual capital", Journal of Intellectual Capital, Vol. 7 No. 1, pp. 5-11.

Orens, R. and Lybaert, N. (2007), "Does the financial analysts' usage of non-financial information influence the analysts' forecast accuracy? Some evidence from the Belgian sell-side financial analyst", International Journal of Accounting, Vol. 42 No. 3, pp. 237271.

Riessman, C. K. (2008), Narrative methods for the human sciences, Sage Publications, London.

Rooney, J. and Dumay, J. (2016), "Intellectual Capital, Calculability and Qualculation", The British Accounting Review, Vol. 48 No. 1, pp. 1-16.

Roos, G., Pike, S. and Fernström, L. (2005), Managing Intellectual Capital in Practice, Elsevier, London.

Roslender, R. and Fincham, R. (2001), "Thinking critically about intellectual capital accounting", Accounting, Auditing and Accountability Journal, Vol. 14 No. 4, pp. 383398.

Schipper, K. (1991), "Analysts' forecasts", Accounting Horizons, Vol. 5 No. 5, pp. 105-121.

Simpson, A. (2010), "Analysts' Use of Nonfinancial Information Disclosures", Contemporary Accounting Research, Vol. 27 No. 1, pp. 249-288. 
Tuckett, D. and Taffler, R. J. (2012), Fund management: An emotional finance perspective, CFA Institute Research Foundation, Charlottesville, VA.

Veltri, S. and Bronzetti, G. (2015), "A Critical Analysis of the Intellectual Capital Measuring, Managing, and Reporting Practices in the Non-profit Sector: Lessons Learnt from a Case Study", Journal of Business Ethics, Vol. 131 No. 2, pp. 305-318.

Wang, J. C. (2008), "Investigating market value and intellectual capital for S\&P 500", Journal of Intellectual Capital, Vol. 9 No. 4, pp. 546-563.

Wang, M.-C. (2015), "Value Relevance of Tobin's Q and Corporate Governance for the Taiwanese Tourism Industry", Journal of Business Ethics, Vol. 130 No. 1, pp. 223-230.

Wang, W.-Y. and Chang, C. (2005), "Intellectual capital and performance in causal models: Evidence from the information technology industry in Taiwan", Journal of Intellectual Capital, Vol. 6 No. 2, pp. 222-236.

Weick, K. E. (1995), Sensemaking in organizations, Sage Publications, London.

Weick, K. E. (2001), Making Sense of Organizations, Blackwell, Oxford.

Weick, K. E. and Browning, L. D. (1986), "Argument and narration in organizational communication", Journal of Management, Vol. 12 No. 2, pp. 243-259.

Youndt, M. A., Subramaniam, M. and Snell, S. A. (2004), "Intellectual capital profiles: an examination of investments and returns", Journal of Management Studies, Vol. 41 No. 2, pp. 335-361.

Yu, A., Garcia-Lorenzo, L. and Kourti, I. (2017), "The role of Intellectual Capital Reporting (ICR) in organisational transformation: A discursive practice perspective", Critical Perspectives on Accounting, Vol. 45, pp. 48-62. 